\title{
EVALUATION OF THE TOTAL FLAVONOID CONTENT AND ANTIMICROBIAL ACTIVITY OF THE TINCTURES OF PROPOLIS OF UKRAINIAN ORIGIN
}

\author{
NATALIIA HUDZ'*, OLEKSII KORYTNIUK², OKSANA YEZERSKA', \\ OLENA MOTYKA ${ }^{3}$, VIRA TURKINA ${ }^{3}$, RAISA KORYTNIUK ${ }^{4}$, \\ and PIOTR P. WIECZOREK ${ }^{5}$
}

'Department of Drug Technology and Biopharmaceutics, Danylo Halytsky Lviv National Medical University, Pekarska St. 69, 79010, Lviv, Ukraine ${ }^{2}$ Department of Occupational and Facial Surgery and Dentistry, Ukrainian Military Medical Academy,

${ }^{3}$ Research Institute of Epidemiology and Hygiene, Danylo Halytsky Lviv National Medical University, Pekarska St. 69, 79010, Lviv, Ukraine

Moskovskaya St. 45/1, Bldg. 33, 01015, Kyiv, Ukraine ${ }^{4}$ Department of Pharmaceutical Technology and Biopharmaceutics, Shupyk National Medical Academy of Postgraduate Education, Dorogozhytska St. 9, 04112, Kyiv, Ukraine

${ }^{5}$ Department of Analytical Chemistry, Faculty of Chemistry, University of Opole, Oleska St 48, 45-052, Opole, Poland

\begin{abstract}
Six tinctures were prepared from four different propolis samples of Ukrainian origin. The total flavonoid content (TFC) in the tinctures and propolis samples was determined by the aluminum-chloride method. The TFC of the propolis samples ranged from $4.78 \%$ to $7.18 \%$ and $11.0 \%$ to $19.5 \%$ with reference to quercetin and rutin, respectively. The TFC of the propolis tinctures was in the range of $4784.31 \mathrm{mg} / \mathrm{L} \pm 8.80 \%$ to $6796.51 \mathrm{mg} / \mathrm{L} \pm 0.52 \%$ and of $10411 \mathrm{mg} / \mathrm{L} \pm 3.47 \%$ to $18499.20 \mathrm{mg} / \mathrm{L} \pm 0.52 \%$ with reference to quercetin and rutin, respectively. The results of the TFC determination indicated a high content of flavonoids in propolis of Ukrainian origin. The best antibacterial activity of four propolis tinctures (three developed tinctures and one purchased tincture) was found against Gram-positive bacteria: $S$. aureus, S. pyogenes and $C$. diphtheriae. The activity of the tinctures against E. coli 25922 ATCC and a clinical isolate of $C$. tropicalis was absent. According to the results of this study, the tinctures of propolis of Ukrainian origin are rich in flavonoids and have good antibacterial activity against Gram-positive microorganisms. These tinctures could be regarded as preparation for the development of antimicrobial medicinal products for the complementary treatment of infectious diseases of the oral cavity.
\end{abstract}

Keywords: propolis, tinctures, flavonoids, antimicrobial activity

Such beekeeping products as honey, bee bread, and propolis have been used for a long time as food products and medical products of traditional medicine (1-6).

Propolis is a well-known resinous material collected by bees from exudates and buds of plants, mixed with pollen, bee enzymes, and wax (7). Propolis is a lipophilic material that is hard and easily broken at room temperature but elastic, soft, and very viscous during warming. It possesses an enjoyable aromatic smell and different colors, including red, green, and brown (8).
Propolis is known in traditional medicine for its numerous pharmacological activities: antibacterial, antifungal, antiviral, antioxidant, antitumor, anti-inflammatory, immunomodulatory, hepatoprotective, wound healing, cytotoxic, etc. (5, 9-14).

Over 500 substances were revealed in propolis up to 2012 (13). Propolis usually contains resins (45-55\%), waxes (up to $25-35 \%$ ), essential and aromatic oils (5-10\%), pollen (5\%), vitamins, microelements, sugars, fatty acids, flavonoids, terpenes (monoterpenes, sesquiterpenes, diterpenes, triterpenes), phenolic acids (caffeic acid, $p$-coumaric

\footnotetext{
* Corresponding author: e-mail: natali_gudz@ukr.net
} 
acid, trans-ferulic acid, trans-cinnamic acid), aminoacids, stilbenes, lignans, coumarins, $n$-alkanes, $n$-alkanes, etc. (12-19).

Among flavonoids are ones of all the classes, especially flavons (luteolin, apigenin, chrysin, and their derivatives), flavonols (macarangin, quercetin derivatives, kaempferol, galangin), flavanones (propolin A, propolin B, propolin E, 2S-naringenin, pinocembrin), chalcones, dihydrochalcones, etc. (12, $13,15,16,20)$. Flavonoids significantly contribute to the pharmacological activities of propolis (antibacterial, antiviral, anti-inflammatory, antioxidant, immunomodulatory properties) $(13,16,17,19,21)$. Therefore, the total flavonoid content (TFC) could be regarded as a criterion for the quality evaluation of propolis and its tinctures $(13,20)$. Moreover, flavonoids and aromatic acid derivatives are stated to show antimicrobial activity $(13,14,21)$. Additionally, there are differences in the chemical composition depending on the country of propolis origin, the season of the propolis collection, and the proximity of herbal recourses to a hive $(15,16,19,21,22)$. Thus, the standardization of propolis seems to be impossible for any identified or unidentified component.

The ethanolic extracts of propolis inhibited the growth of Staphylococcus aureus, Enterococcus spp., Bacillus cereus, Candida yeasts $(17,19,23)$. It is supposed that the antimicrobial activity mechanism is complex and could be attributed to the synergic effect of phenolic substances, especially flavonoids and esters of phenolic acids $(13,17,19$, $21,24)$.
Propolis administration reduces the use of antipyretics and anti-inflammatory medicinal products, and the rate of evolution to tracheitis, bronchitis, and rhinosinusitis at viral pharyngitis (25). The ethanolic extract of propolis (a ratio of propolis to the extract was 1 to $10,70 \%$ ethanol as a solvent) improved the total mitochondrial respiratory efficiency in human spermatozoa in vitro (12). The propolis extract synergically increases the efficacy of antibiotics, including vancomycin and oxacillin against drug-resistant microorganisms (methicillinresistant S. aureus, Streptococcus pneumoniae, Streptococcus pyogenes) $(14,15)$. Propolis was stated as a healing subsidiary component for the administration of oral hygiene (14). Propolis from Pakistan has good antimicrobial activity against such pigmented anaerobic periodontal pathogens as Porphyromonas asaccharolytica, Porphyromonas gingivalis, Prevotella intermedia, and Prevotella melaninogenica (26).

As a rule, for studies authors employ extracts of propolis prepared in a ratio of propolis to a final extract as 1 to 10 , using $70 \%$ ethanol, heating, and maceration for $24 \mathrm{~h}(12,15,16)$.

To the best of our knowledge, there a few studies related to the determination and standardization of TFC in propolis tinctures and screening of antimicrobial activity of propolis of Ukrainian origin. Moreover, there are few studies related to the antimicrobial activity of propolis against Corynebacterium diphtheriae NCTC10356 and a clinical isolate of fungus Candida tropicalis. These stan-

Table 1. Developed tinctures of propolis of Ukrainian origin.

\begin{tabular}{|c|c|c|c|c|c|c|}
\hline $\mathrm{N}$ & $\begin{array}{c}\text { Identification } \\
\text { of } \\
\text { tincture }\end{array}$ & $\begin{array}{c}\text { Detailed } \\
\text { characteristics } \\
\text { of propolis }\end{array}$ & $\begin{array}{l}\text { Quantity } \\
\text { of } \\
\text { components }\end{array}$ & Technology & $\begin{array}{l}\text { Ratio of } \\
\text { propolis to } \\
\text { tincture }\end{array}$ & Note \\
\hline $\mathrm{T} 1$ & 103180 & $\begin{array}{c}\text { Collection from } 16 \text { September } \\
\text { 2017, unpurified, Mykolaiv } \\
\text { region }\end{array}$ & $\begin{array}{l}5.01 \mathrm{~g}: 60 \mathrm{~mL} \\
60 \% \text { ethanol }\end{array}$ & \multirow{6}{*}{$\begin{array}{c}\text { At a } \\
\text { temperature of } \\
40 \text { to } 50^{\circ} \mathrm{C} \\
\text { for } 200 \text { min plus } \\
\text { at room } \\
\text { temperature } \\
\text { for } 21 \mathrm{~h}\end{array}$} & $1: 10.88$ & - \\
\hline $\mathrm{T} 2$ & $10120 \mathrm{~S}$ & \multirow{2}{*}{$\begin{array}{c}\text { Collection from August 2019, } \\
\text { unpurified, Poltava region }\end{array}$} & $\begin{array}{l}2.70 \mathrm{~g}: 30 \mathrm{~mL} \\
70 \% \text { ethanol }\end{array}$ & & $1: 10.20$ & - \\
\hline $\mathrm{T} 3$ & $10320 \mathrm{~S}$ & & $\begin{array}{l}2.50 \mathrm{~g}: 28 \mathrm{~mL} \\
70 \% \text { ethanol }\end{array}$ & & $1: 10.0$ & \multirow{2}{*}{$\begin{array}{c}\text { Simultaneous } \\
\text { preparation; } \\
\text { tincture } \\
\text { 10320S is } \\
\text { more yellow }\end{array}$} \\
\hline $\mathrm{T} 4$ & 203200 & $\begin{array}{l}\text { Collection from April } 2019 \\
\text { unpurified, Mykolaiv region }\end{array}$ & $\begin{array}{l}2.50 \mathrm{~g}: 28 \mathrm{~mL} \\
70 \% \text { ethanol }\end{array}$ & & $1: 10.0$ & \\
\hline T5 & $40420 \mathrm{~S}$ & \multirow{2}{*}{$\begin{array}{c}\text { Collection from } \\
\text { August } 2018, \\
\text { unpurified, } \\
\text { Poltava region }\end{array}$} & $\begin{array}{l}5.02 \mathrm{~g}: 55 \mathrm{~mL} \\
70 \% \text { ethanol }\end{array}$ & & $1: 10.54$ & \multirow{2}{*}{$\begin{array}{l}\text { The same } \\
\text { sample of } \\
\text { propolis } \\
\text { was used }\end{array}$} \\
\hline T6 & $50520 \mathrm{~S}$ & & $\begin{array}{l}10.06 \mathrm{~g}: \\
111 \mathrm{~mL} 70 \% \\
\text { ethanol }\end{array}$ & & $1: 9.94$ & \\
\hline
\end{tabular}


dardized tinctures could be regarded as antimicrobial, anti-inflammation, and immunomodulation preparations for the oral drug administration and oral hygiene $(14,26)$. Therefore, the purpose of our study was to elaborate propolis tinctures and analytical procedure for the evaluation of the developed tinctures and study their stability, and conduct screening for the antimicrobial activity of the tinctures of propolis of Ukrainian origin.

\section{MATERIALS AND METHODS}

\section{Chemicals and Reagents}

All the chemicals and solvents used for analyses were of analytical purity grade. Ethanol and aluminum chloride hexahydrate were purchased from $\mathrm{POCH}$ S.A. (Gliwice, Poland). The rutin and quercetin were purchased from Sigma-Aldrich (Poznan, Poland).

\section{Material}

Crude propolis was collected from two regions of Ukraine in 2017-2019 (four samples). The propolis samples were kept at a temperature of $2-8^{\circ} \mathrm{C}$ before the tincture preparation.

\section{Extraction}

All the tinctures were obtained in a ratio of propolis to a final tincture as approximately 1 to 10 . As a solvent, $70 \%$ ethanol was used. The mixtures were in closed containers at a temperature of 40$50^{\circ} \mathrm{C}$ for $200 \mathrm{~min}$ with the following extraction at room temperature for $21 \mathrm{~h}$. After this period the residue was separated from the extraction solvent by means of filtration through a paper filter. Therefore, the total period of maceration was $24 \mathrm{~h}(3 \mathrm{~h}+21 \mathrm{~h}$ $=24 \mathrm{~h}$ ). The characteristics of the propolis samples and prepared tinctures are presented in Table 1.

\section{Total flavonoid content (TFC)}

TFC was evaluated by the colorimetric method as flavones, isoflavones, and flavonols form stable complexes with aluminum chloride according to C.-C. Chang et al. and Falcão et al. $(5,20)$. TFC was determined using the slightly modified analytical procedures of differential spectrometry provided by A. Meda et al. for the quality evaluation of the TFC in honey (27) and by N. Hudz et al. for bee bread and Satureja montana tinctures $(2,28)$. The Quercetin dihydrate and rutin trihydrate dissolution in 50\% ethanol was carried out with the aid of ultrasound and temperature. The results were expressed as $\mathrm{mg}$ quercetin or rutin equivalents per one liter of a tincture $(\mathrm{mg} / \mathrm{L})$ or $\%$ quercetin or rutin equivalents in the samples of propolis $(\%)$.
$50 \mu \mathrm{L}$ of a stock solution of rutin trihydrate $(1000 \mathrm{mg} / \mathrm{L})$ were mixed with $0.95 \mathrm{~mL}$ of $50 \%$ ethanol and $1.0 \mathrm{~mL}$ of $2 \%$ aluminum chloride hexahydrate in $50 \%$ ethanol. After incubation at room temperature for $65 \pm 5 \mathrm{~min}$, the spectra of the reaction mixtures were measured in the range of $360 \mathrm{~nm}$ to $460 \mathrm{~nm}$ with spectrophotometer 'Photometry Hitachi U-2810', The volume of $2 \%$ aluminum chloride hexahydrate in $50 \%$ ethanol was substituted by the same volume of $50 \%$ ethanol in the blank for rutin trihydrate. In a like manner, $50 \mu \mathrm{L}$ of the diluted developed tinctures of propolis (1 to 20) were diluted with $50 \%$ ethanol up to $1.0 \mathrm{~mL}$ and was mixed with 1.0 of $2 \%$ solution of aluminum chloride hexahydrate. The mixture was mixed by vortex and incubation was done at room temperature for $65 \pm 5$ min. The volume of $2 \%$ solution of aluminum chloride was substituted by the same amount of $50 \%$ ethanol in the blank. The test was carried out for each tincture in triplicate.

TFC with reference to rutin was calculated using the following formula:

$$
\mathrm{C}=\mathrm{A}_{\text {test }} \times \mathrm{m} \times 1000 \times \mathrm{k} /\left(\mathrm{A}_{\mathrm{R}} \times \mathrm{V}_{\mathrm{R}}\right),
$$

where $\mathrm{C}$ is TFC of the tested tincture $(\mathrm{mg} / \mathrm{L}), \mathrm{A}_{\text {test }}$ is the absorbance of the reaction mixture of the tincture at the absorption maximum, $A_{R}$ is the absorbance of the reaction mixture of rutin trihydrate solution in a concentration of $50 \mathrm{mg} / \mathrm{L}$ at the absorption maximum $\left(\lambda_{\max }=412 \mathrm{~nm}\right), \mathrm{m}(\mathrm{mg})$ is mass of rutin trihydrate for the preparation of the stock solution (approximately $1000 \mathrm{mg} / \mathrm{L}$ ), $\mathrm{k}$ is coefficient for the recalculation of rutin trihydrate into rutin (0.917) and dilution of the tinctures (20 times), $\mathrm{V}_{\mathrm{R}}$ is a volume in which rutin was dissolved. For computing with reference to quercetin, we employed the same analytical procedure, taking 50 $\mu \mathrm{L}$ of a stock solution of quercetin dihydrate (432 $\mathrm{mg} / \mathrm{L})$. TFC with reference to quercetin was calculated, using the following formula: $\mathrm{C}=\mathrm{A}_{\text {test }} \times \mathrm{m} \times$ $1000 \times \mathrm{k} /\left(\mathrm{A}_{\mathrm{Q}} \times \mathrm{V}_{\mathrm{Q}}\right)$, where $\mathrm{C}$ is TFC of the tested tincture $(\mathrm{mg} / \mathrm{L}), \mathrm{A}_{\text {test }}$ is the absorbance of the reaction mixture of the tincture at the absorption maximum, $A_{Q}$ is the absorbance of the reaction mixture of quercetin dihydrate solution in a concentration of $21.6 \mathrm{mg} / \mathrm{L}$ at the absorption maximum $\left(\lambda_{\max }=426\right.$ $427 \mathrm{~nm}), \mathrm{m}(\mathrm{mg})$ is mass of quercetin dihydrate for the preparation of the stock solution (approximately $432 \mathrm{mg} / \mathrm{L}), \mathrm{k}$ is coefficient for the recalculation of quercetin dihydrate into quercetin (0.894) and dilution of the tinctures (20 times), $\mathrm{V}_{\mathrm{Q}}$ is a volume in which quercetin dihydrate was dissolved. 


\section{Screening antimicrobial activity}

For this study, we used the procedure described by Serrano et al. for herbal extracts and essential oils (29). The antimicrobial activity of three developed propolis tinctures and one tincture purchased in a pharmacy (Ukrainian manufacture "Ternopil pharmaceutical factory", lot 30216) was evaluated against microorganisms. The tested microorganisms were Gram-positive bacteria: Staphylococcus aureus ATCC 25923, C. diphtheriae NCTC 10356, clinical isolates of methicillin-resistant (MR) S. aureus and $S$. pyogenes (2 isolates), Gram-negative bacterium: Escherichia coli ATCC 25922, and fungus C. tropicalis isolated from a female patient. The preparation of inoculates and media was carried out in accordance with EUCAST guidelines $(30,31)$.

Sterile filter discs (diameter $6 \mathrm{~mm}$, manufacture "Aspect", Ukraine) were impregnated with 20, 40 and $60 \mu \mathrm{L}$ of four tinctures of propolis and $0.12 \%$ solution of chlorhexidine digluconate and dried in the air. Impregnating the discs with 40 and $60 \mu \mathrm{L}$ was conducted using $20 \mu \mathrm{L}$ with the following drying and putting again $20 \mu \mathrm{L}$. Then dried discs were placed on the surface of Mueller-Hinton agar for $S$. aureus, E. coli, S. pyogenes and $C$. diphtheria, and Sabouraud agar (Merck, Darmstadt, Germany) for C. tropicalis. The treated Petri dishes with $S$. aureus and E. coli were incubated at a temperature of $37^{\circ} \mathrm{C}$ for $24 \mathrm{~h}$, with $S$. pyogenes and C. diphtheriae for 48 h, and with $C$. tropicalis at a temperature of $30^{\circ} \mathrm{C}$ for $24 \mathrm{~h}$.

The antimicrobial activity was evaluated by measuring the growth inhibition zone diameter, including the disc diameter. The standard discs with antimicrobial drugs (penicillin G, amikacin, ampicillin, pefloxacin, tetracycline) were used for the quality control of the experiments. Each experiment was carried out in triplicate.

\section{Statistical analysis}

Values were expressed as means \pm standard deviation for the TFC in propolis tinctures and samples and for antimicrobial activity and means \pm relative standard deviation (for the TFC in propolis tinctures).

Wayne's statistical analysis was used for comparison of the TFC mean values obtained in different days, for different samples of propolis, etc. The decision rule in all cases was: with $\alpha=0.025$, critical values of $t *$ should be in the range of -2.78 to +2.78. Null hypothesis $\left(\mathrm{H}_{0}\right)$ was denied if $\mathrm{t}^{*}<-2.78$ or $t^{*}>+2.78(2,28,33)$.

\section{RESULTS AND DISCUSSION}

The propolis samples of Ukrainian origin and respectively tinctures are rich in flavonoids. The TFC ranged from $4.78 \%$ to $7.18 \%$ and $11.0 \%$ to $19.5 \%$ with reference to quercetin and rutin, respectively. The TFC of the propolis tinctures was in the range of $4784.31 \mathrm{mg} / \mathrm{L} \pm 8.80 \%$ to $6796.51 \mathrm{mg} / \mathrm{L} \pm$ $0.52 \%$ and of $10411 \mathrm{mg} / \mathrm{L} \pm 3.47 \%$ to 18499.20 $\mathrm{mg} / \mathrm{L} \pm 0.52 \%$ with reference to quercetin and rutin, respectively. The results of that study indicated a high content TFC in propolis of Ukrainian origin. According to C.-C. Chan, the TFC of three Taiwan samples, one Brazil sample, and two Chinese samples, ranged from 2.82 to $7.73 \%$ with reference to quercetin (20). Therefore, our studies are in line with the studies of C.-C. Chan et al. Chan et al. also provide the results for three propolis tinctures: the TFC was in the range of $1.02 \%$ to $1.47 \%$ with refe-

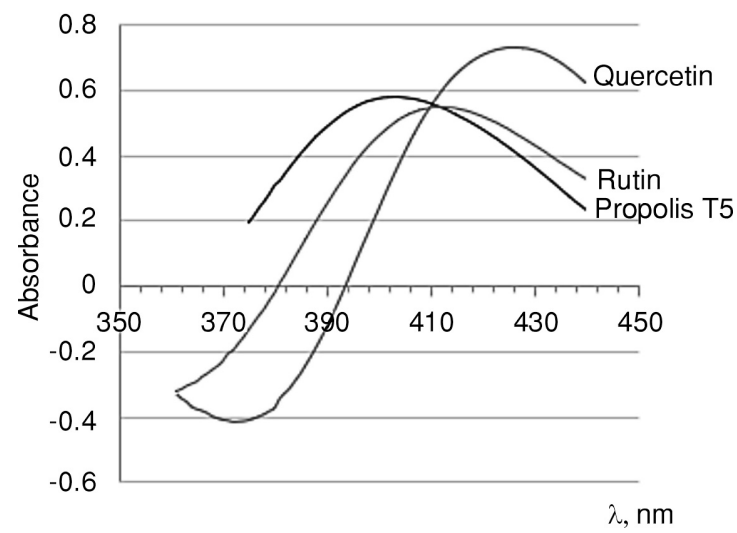

Figure 1. Differential spectra of rutin trihydrate $(50 \mathrm{mg} / \mathrm{L})$, quercetin dihydrate $(21 \mathrm{mg} / \mathrm{L})$, and the propolis tincture T5. 


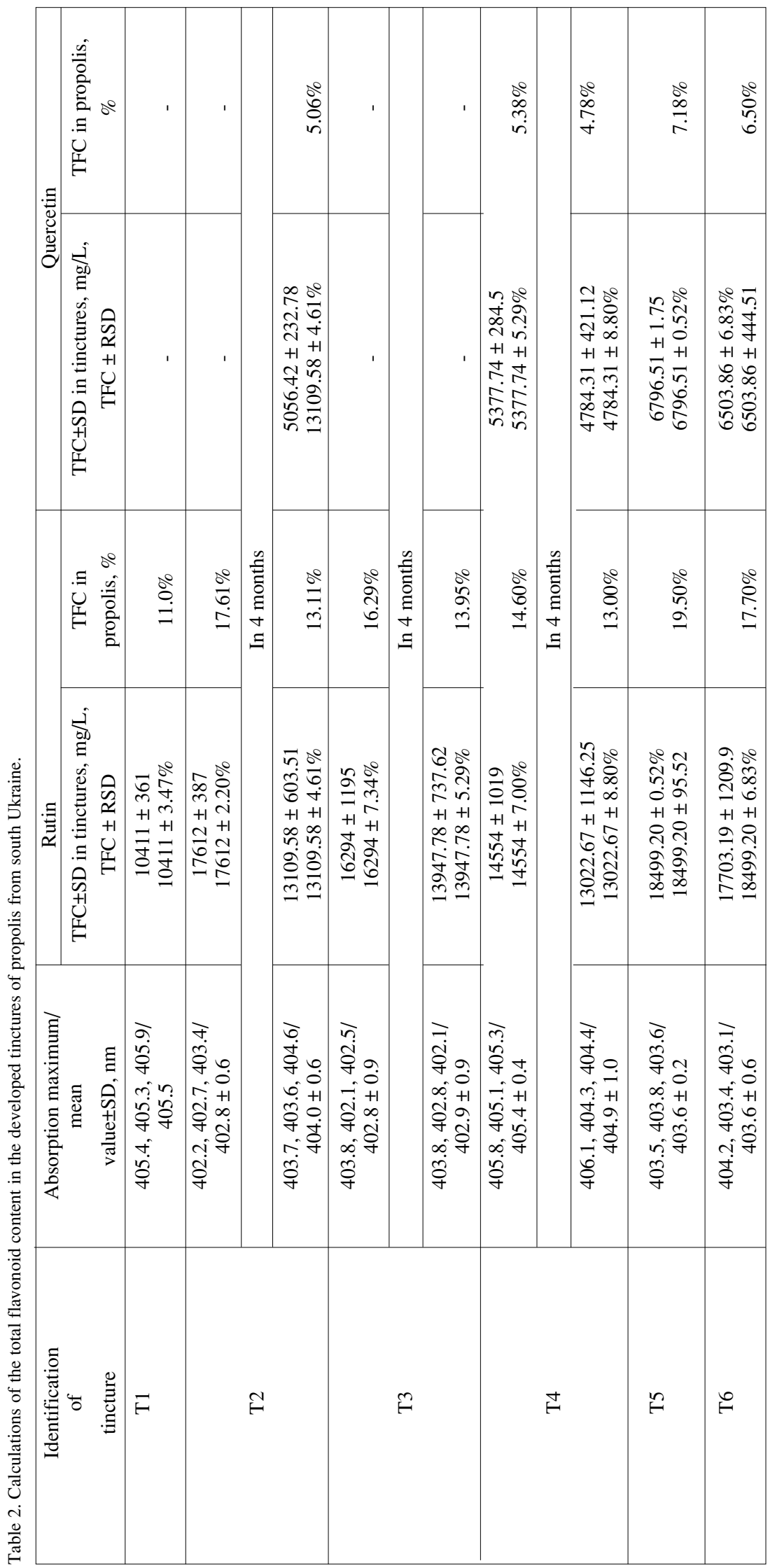




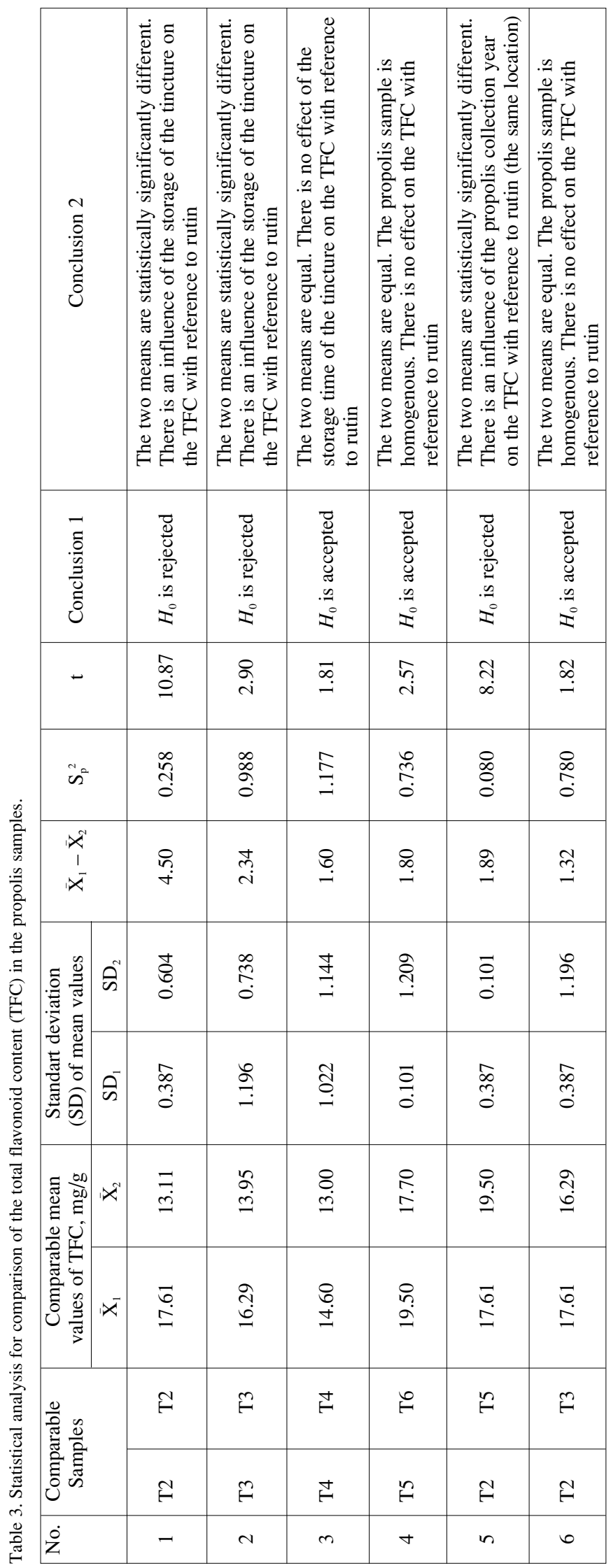


rence to quercetin. However, these authors did not state the ratio of propolis to a final tincture. In our studies, the TFC of the tinctures was in the range of 0.48 to $0.68 \%$ with reference to quercetin (4784.31 $\mathrm{mg} / \mathrm{L} \pm 8.80 \%$ to $6796.51 \mathrm{mg} / \mathrm{L} \pm 0.52 \%$ with reference to quercetin).

Quercetin or rutin were chosen as commercially available reference standards. Moreover, a lot of authors use quercetin for the TFC determination in propolis samples by the aluminum spectrophotometric method $(15,20,34,35)$. Bakchiche et al. employed rutin (36). Furthermore, quercetin and rutin were revealed in propolis (37).

Al-Ani et al. state that the TFC of the Irish propolis was $2.86 \pm 0.2 \mathrm{mg}$ quercetin equivalents per gram of the propolis extract while the Germany and Czech Republic samples contain approximately $2 \mathrm{mg}$ per gram of propolis (15). Moreover, the technology of the ethanol propolis extract preparation was similar to our one for such parameters $(70 \%$ ethanol, a ratio of propolis to the extract was 1 to $10,24 \mathrm{~h}$ of maceration). Wang X. et al. determined from 21 to $53 \mathrm{mg}$ quercetin equivalent per gram of the ethanolic extract of propolis (the Brazilian, Chinese, Australian, and Korean propolis samples) (35).

However, we could not compare these results with our ones as computing was given for propolis extract after special sample preparation (extraction, ethanol evaporation, and dilution for the TFC determination). Furthermore, these authors compare results for propolis of different origins not giving absolute values of the TFC. The computing of TFC is more complicated comparing different results obtained with different standards, for example, quercetin and galangin. Falcão et al. give results for flavones/flavonols and flavanones/dihydroflavonols in the range of 5-114 mg galangin equivalents per $\mathrm{g}$ of propolis extract and 35-118 mg pinocembrin equivalents per $g$ of extract respectively, while the TFC range from 50 to $232 \mathrm{mg} / \mathrm{g} \mathrm{(5).}$

Zarate H. et al. state about a high content in the propolis from Mexica (various areas of Guanajuato). The TFC was in the range of 13 to $379 \mathrm{mg}$ of quercetin equivalents per $\mathrm{g}$ of propolis (1.3-39.9\%) (34). Bakchiche et al. state about a low TFC (379 mg rutin per $100 \mathrm{~g}$ sample, namely $0.379 \%$ of rutin equivalents) in the propolis from the south of Algeria (36).

Therefore, the TFC of propolis depends on an analytical procedure of the TFC determination, including a wavelength for measurements, reference standard, origin, way of computing, etc. It seems that it is impossible to compare the results expressed in different equivalents.
The TFC of tinctures and recalculations for the crude propolis samples with reference to quercetin and rutin are given in Table 2.

In our studies we used the absorption maximum of the reaction mixtures of the tinctures with aluminum chloride for the TFC determination, namely, we measured the absorbance of the reaction mixtures of the tinctures and reference standards in their absorption maxima. Speaking about the spectra of the reaction mixtures of the tinctures with aluminum chloride, it can be seen that these mixtures showed the absorption maximum in the range of $402.8 \mathrm{~nm}$ to $405.5 \mathrm{~nm}$ (Table 2, Fig. 1). A hypsochromic shift of the tinctures compared to rutin $\left(\lambda_{\max }=412 \mathrm{~nm}\right)$ and quercetin $\left(\lambda_{\max }=426-427 \mathrm{~nm}\right)$ could be explained by the presence of flavones in propolis, especially luteolin, apigenin, chrysin, and their glycosides, having an absorption maximum in the range of 385-395 $\mathrm{nm}(2,15,16,20,28)$.

Chan et al., Al-Ani et al., and Zarate et al. used a wavelength of $415 \mathrm{~nm}$ for measurements $(15,20$, 34). Wang X. used a wavelength of $435 \mathrm{~nm}$. Al-Ani et al., Zarate et al., and Wang X. did not explain why they chose such a wavelength $(15,34,35)$. Moreover, these authors used quercetin for computing $\operatorname{TFC}(15,34,35)$. Additionally, Al-Ani et al. did not conduct calculations for the TFC determination in the propolis samples. They just compare the TFC in samples of Irish, Czech, and Germanic origin according to their elaborated analytical procedure. Falcão et al. used also a wavelength $415 \mathrm{~nm}$ for measurements and galangin as a reference standard (15).

Therefore, on the one hand, we employed two reference standards for easier comparison of our results with ones obtained by other authors. On the other hand, we used rutin as a reference standard because of the proximity of its absorption maximum to one of the tinctures after adding aluminum chloride.

Null hypothesis testing was employed for the comparison of two mean values of the TFC per $1 \mathrm{~g}$ of propolis obtained for the tinctures which are differed in year of the propolis collection, data of the TFC determination, and preparation of the tinctures from the same sample of propolis, etc. In all the cases the null hypothesis $\left(H_{0}\right)$ was tested that the difference is equal to zero, namely, two means were regarded the same at $H_{0}\left(\mu_{1}=\mu_{2}\right)$ (Table 3).

As can be seen from Table 3, the year of the propolis collection has a significant influence on the TFC (line 5) while the part of the propolis sample used for the preparation of tinctures does not influence the TFC. Therefore, it can be concluded that 
the propolis samples are homogenous (lines 4 and $6)$.

Additionally, it was observed that there is a noticeable decrease in the TFC after 4 months that needs further studies in order to set up a storage period of propolis tinctures. The statistical analysis showed that in 2 cases of 3 there is a decrease in the tinctures TFC during storage (lines 1-3).

Propolis is a beekeeping product rich in flavonoids with known antimicrobial activity. Our results of the antimicrobial activity of the propolis tinctures are provided in Table 4.

As can be seen from table 4, the propolis tinctures evaluated in this study showed antibacterial activity against Gram-positive bacterial pathogens: $S$. aureus, including MR $S$. aureus, $S$. pyogenes and C. diphtheriae. We observe the logical dependence of an increase in the inhibition zones on a volume of the tinctures and chlorhexidine put on the discs. Our study is in line with studies of Al-Ani et al. (15). Irish propolis demonstrated significant bactericidal activity against Gram-positive bacteria (S. pyogenes and Bacillus subtilis) (15).

E. coli and clinical isolate $C$. tropicalis were highly resistant to the propolis tinctures. The inhibition zones were absent that completely coincided with studies of Al-Ani et al. who stated that $P$. aeruginosa and E. coli were highly resistant to the propolis extracts (Irish, Czech, and German origin). The ethanolic extracts of propolis from Ireland and Czech showed a good fungicidal effect. The minimum fungicidal concentrations were in the range of $0.1 \mathrm{mg} / \mathrm{mL}$ to $2.5 \mathrm{mg} / \mathrm{mL}$, while propolis of German origin showed mostly fungistatic activity.

Table 4. Antimicrobial activity of four tinctures of propolis.

\begin{tabular}{|c|c|c|c|c|c|c|c|c|c|c|c|}
\hline \multirow[b]{2}{*}{ Volume, $\mu \mathrm{L}$} & \multicolumn{11}{|c|}{ Inhibitions zones diameter, $\mathrm{mm}$} \\
\hline & 2 & 3 & 4 & 5 & 1 & Chl & Pen & Ak & Pef & Tet & Amp \\
\hline \multicolumn{12}{|c|}{ Staphylococcus aureus ATCC 25923} \\
\hline 20 & 11 & 10 & 9 & 11 & 0 & 14 & \multirow{3}{*}{34} & \multirow{3}{*}{24} & \multirow{3}{*}{28} & \multirow{3}{*}{26} & \multirow{3}{*}{ - } \\
\hline 40 & 11 & 10 & 10 & 11 & 0 & 15.5 & & & & & \\
\hline 60 & 10 & 9 & 9 & 10 & 0 & 18 & & & & & \\
\hline \multicolumn{12}{|c|}{ MR Staphylococcus aureus } \\
\hline 20 & 11 & 11 & 11.5 & 12.5 & 0 & 15 & \multirow{3}{*}{0} & \multirow{3}{*}{24} & \multirow{3}{*}{25} & \multirow{3}{*}{25} & \multirow{3}{*}{ - } \\
\hline 40 & 12 & 12.5 & 12 & 13.5 & 0 & 17 & & & & & \\
\hline 60 & 13.5 & 13.5 & 11 & 14 & 0 & 20 & & & & & \\
\hline \multicolumn{12}{|c|}{ Corynebacterium diphtheriae NCTC 10356} \\
\hline 20 & 10 & 10 & 10 & 10.5 & 0 & 15 & \multirow{3}{*}{27} & \multirow{3}{*}{26} & \multirow{3}{*}{28} & \multirow{3}{*}{26} & \multirow{3}{*}{26} \\
\hline 40 & 11 & 11 & 11 & 11 & 0 & 18 & & & & & \\
\hline 60 & 12 & 13 & 12 & 13 & 0 & 20 & & & & & \\
\hline \multicolumn{12}{|c|}{ Streptococcus pyogenes (two isolates) } \\
\hline 20 & 12 & 12 & 10.5 & 12 & 0 & 16 & \multirow{3}{*}{35} & & & & \multirow{3}{*}{35} \\
\hline 40 & 13 & 12 & 12 & 13 & 0 & 20 & & & & & \\
\hline 60 & 15 & 15 & 15 & 16 & 0 & 24 & & & & & \\
\hline \multicolumn{12}{|c|}{ Candida tropicalis } \\
\hline 20 & \multirow{2}{*}{\multicolumn{4}{|c|}{ Inhibition zones are absent }} & 0 & 9 & \multirow{3}{*}{-} & \multirow{3}{*}{-} & \multirow{3}{*}{-} & \multirow{3}{*}{ - } & \multirow{3}{*}{-} \\
\hline 40 & & & & & 0 & 12.5 & & & & & \\
\hline 60 & 8 & 0 & 0 & 8 & 0 & 15 & & & & & \\
\hline & & & & scheric & coli & $\mathrm{CC} 25$ & & & & & \\
\hline 20 & & & & & 0 & 12 & & & & & \\
\hline 40 & & nhibition & es are & & 0 & 12 & - & 24 & 28 & - & 27 \\
\hline 60 & & & & & 0 & 25.5 & & & & & \\
\hline
\end{tabular}

Chl - 0.12\% solution of chlorhexidine digluconate, Pen - penicillin, Ak - amikacin, Pef - perfloxacin, Tet - tetracyclin, Amp - ampicillin; $1-70 \%$ ethanol; 2, 3, 4, 5 - tinctures T6, T2, a purchased tincture in a pharmacy and T1, respectively. SD ranged from 0.5 to 2.0 mm. The inhibition zones of C. tropicalis are $24 \mathrm{~mm}$ for nystatin, $28 \mathrm{~mm}$ for fluconazole (there was a growth of small colonies in the inhibition zone), $20 \mathrm{~mm}$ for itraconazole, and $26 \mathrm{~mm}$ for miconazole. 

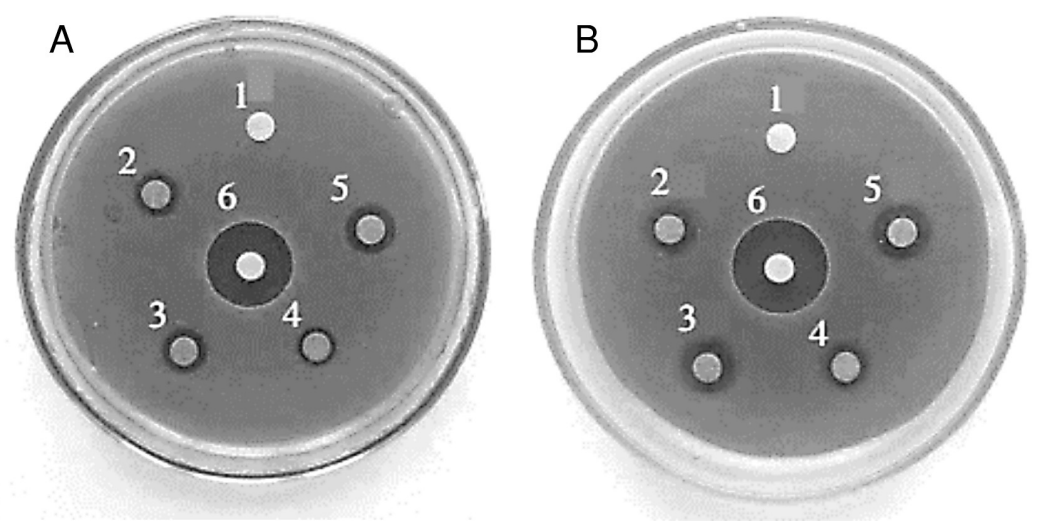

Figure 2. Inhibition zones for MR S.aureus (A) and S.aureus ATCC 25923 (B): 1 - ethanol; 2, 3, 4, 5 - tinctures T6, T2, a purchased tincture and $\mathrm{T} 1(60 \mu \mathrm{L}) ; 6-0.12 \%$ chlorhexidine digluconate (in the center of the Petri dishes).

Our study also partly corresponded to the studies performed by Kujumgiev et al. with propolis from Bulgaria, Albania, Mongolia, Egypt, Brazil, and Canary Islands. Kujumgiev et al. revealed that propolis samples were not active against the $E$. coli and were active against $C$. albicans (19). According to Marcucci, the ethanol extract of propolis inhibited Candida and all tested dermatophytes (14).

It is worth noting that $C$. tropicalis demonstrated a partial resistance even to fluconazole despite the inhibition zone of $28 \mathrm{~mm}$ as there was a growth of small colonief in the inhibition sone. Thus, we can suppose that the propolis of Ukrainian origin does not possess antifungal activity against the used clinical isolate of $C$. tropicalis.

The ethanolic extracts of propolis of Brazilian origin have a more pronounced activity against Gram-positive bacteria (Staphylococcus sp. and Streptococcus mutans) and Candida albicans ATCC 10231, and a less evident activity against Gram-negative and Candida albicans FT2010 (23).

Przybyłek I. and Karpiński T.M. state about the greater activity of propolis against Gram-positive bacteria compared to Gram-negative ones (38).

The control experiments with $70 \%$ ethanol showed that it does not have any activity. This is obvious as $70 \%$ ethanol was previously evaporated from discs. The drawback of this study is the absence of the influence of ethanol. It does not express a real administration of propolis tinctures in real clinical conditions. It could be supposed that the antimicrobial activity of the combination of propolis and $70 \%$ ethanol would be stronger. The second drawback is overlooking hydrophobic propolis components with antimicrobial activity in the method of diffusion in agar. Therefore, we consider these studies as preliminary or antimicrobial screening of the propolis tinctures.

We would like to note that similar antimicrobial activities were observed for the tinctures of different samples of propolis and TFC in the tinctures. It is supposed that there are some still unknown, but common for all types of propolis, compounds which induce antimicrobial activity not depending on the propolis origin. One more drawback of this study is the non-testing of the purchased tincture for TFC. However, this tincture and $\mathrm{T} 1$ were tested for the total phenolic contents, which were similar, respectively, $14200 \mathrm{mg} / \mathrm{L}$ and $15849 \mathrm{mg} / \mathrm{L}$ (with reference to gallic acid) (32). Moreover, we determined the total phenolic content of one more purchase tincture of the same manufacture (lot 20216) which was $16586 \mathrm{mg} / \mathrm{L}$.

\section{CONCLUSION}

The TFC measured by the spectrophotometric method can be used as a key index for the quality evaluation of propolis and its tinctures for pharmaceutical usage. The TFC was determined using the reaction of forming a complex of flavonoids with aluminum chloride. Propolis of Ukrainian origin is rich in flavonoids. The tinctures of propolis exhibit antimicrobial activity against $S$. aureus, $S$. pyogenes and $C$. diphtheria. Our studies also confirmed the absence of the antibacterial activity of propolis against E. coli and C. tropicalis. These studies are ground for the development of sprays with antibacterial activity against $S$. aureus, $S$. pyogenes and $C$. diphtheria for the complementary therapy of infection disorders of the oral cavity. 
Further studies will be directed at the synergic activity of propolis tinctures and known antimicrobials drugs, and the development and studies of antimicrobial sprays on the base of propolis tinctures for the oral cavity. Currently, allergic screening of the sprays with the propolis tincture and herbal preparations are being performed.

\section{Acknowledgment}

Co-author Nataliia Hudz thanks the International Visegrad Fund for the scholarship for the research related to the development of sprays on the base of natural products and performed at the University of Opole (Poland). The coathours are thankful to S. Velichko and O. Tkachenko for providing with the propolis samples from Poltava and Mykolaiv regions, respectively.

\section{Conflict of interest}

The authors declare no conflict of interest.

\section{REFERENCES}

1. Hudz N., Ivanova R., Brindza J., Grygorieva O., Schubertová Z., et al.: Potravinarstvo Slovak J. Food Sci. 11, 480 (2017).

2. Hudz N., Yezerska O., Grygorieva O., Brindza J., Felšöciová S., et al.: Acta Pol. Pharm. 76, 439 (2019).

3. Stanek N., Jasicka-Misiak I.: Food Anal. Methods. 11, 2979 (2018).

4. Jasicka-Misiak I., Gruyaert S., Poliwoda A., Kafarski P.: J. Chem. 2017, 5393158 (2017).

5. Falcão S., Freire C., Vilas-Boas M.: J. Am. Oil Chem. Soc. 90, 1729 (2013).

6. Živković J., Sunarić S., Stanković N., Mihajilov-Krstev T., Spacić A.: Acta Pol. Pharm. 76, 671 (2019).

7. Sforcin J.M.: Phytother. Res. 30, 894 (2016).

8. Rebiai A., Belfar M.L., Mesbahi M.A., Nani S., Tliba A., et al.: J. Fund App. Sci. 9, 1656 (2017).

9. Kurek-Górecka A., Rzepecka-Stojko A., Górecki M., Stojko J., Sosada M., et al.: Molecules 19, 78 (2013).

10. Viuda-Martos M., Ruiz-Navajas Y., FernándezLópez J., Pérez-Alvarez J.A.: J. Food Sci. 73, 117 (2008).

11. Shimizu T., Hino A., Tsutsumi A., Yong K.P., Watanabe W.. et al.: Antivir. Chem. Chemother. 19, 7 (2008).

12. Cedikova M., Miklikova M., Stachova L., Grundmanova M., Tuma Z., et al.: Evid. Based
Complement. Alternat. Med. 2014, 248768 (2014).

13. Huang S., Zhang C.P., Wang K., Li G.Q., Hu F.L.: Molecules 19, 19610 (2014).

14. Marcucci M.C.: Apidologie 26, 83 (1995).

15. Al-Ani I., Zimmermann S., Reichling J., Wink M.: Medicines 5, 2 (2018).

16. Abd El Hady F.K., Hegazi A.G.: Z. Naturforsch. C. J. Biosci. 57, 386 (2002).

17. Sarýçoban C., Yerlikaya S.: J. Agroaliment. Proc. Tech. 22, 56 (2016).

18. Rushdi A.I., Adgaba N., Bayaqoob N.I., AlKhazim A., Simoneit B. et al.: SpringerPlus. 3, 253 (2014).

19. Kujumgiev A., Tsvetkova I., Serkedjieva Y., Bankova V., Christov R. et al.: J Ethnopharmacol. 64, 235 (1999).

20. Chang C.-C., Yang M.-H., Wen H.-W., Chern J.-C., Zieliński A., et al.: J. Food Drug Anal. 10, 178 (2002).

21. Urushisaki T., Takemura T., Tazawa S., Fukuoka M., Hosokawa-Muto J. et al.: Evid. Based Complement. Alternat. Med. 2011, 254914 (2011).

22. Schnitzler P., Neuner A., Nolkemper S., Zundel C., Nowack H., et al.: Phytother. Res. 24, 20 (2010).

23. Rezende G.P.S.R., Pimenta F.C., Costa L.R.R.S.: Braz. J. Oral Sci. 5, 967 (2006).

24. Ramanauskiene K., Inkeniene A.M., Savickas A., Masteikova R., Brusokas V.: Acta Pol. Pharm. 66, 681 (2009).

25. Di Pierro F., Zanvit A., Colombo M.: Int. J. Gen. Med. 9, 409 (2016).

26. Shabbir A., Rashid M., Tipu H.N.: Cureus 8, 682 (2016).

27. Meda A., Lamien C.E., Romito M., Millogo J., Nacoulma O.G.: Food Chem. 91, 571 (2005).

28. Hudz N., Makowicz E., Shanaida M., et al.: Molecules. 25, 4763 (2020).

29. Serrano C., Matos O., Teixeira B., Ramos C., Neng N., et al.: J. Sci. Food Agric. 91, 1554 (2011).

30. EUCAST Disk Diffusion Method for Antimicrobial Susceptibility Testing - Version 8.0, 2020. http://www.eucast.org.

31. The European Committee on Antimicrobial Susceptibility Testing. Breakpoint tables for interpretation of MICs for antifungal agents, version 10.0, 2020. ttp://www.eucast.org/astoffungi/clinicalbreakpointsforantifungals.

32. Hudz N., Tkachenko O., Brindza J.: Agrobiodiversity for Improve the Nutrition, Health and Quality of Human and Bees Life: Book of Abstracts of the 4th International Scientific 
Conference. 40 (2019).

33. Wayne, W.D. Biostatistics: A Foundation for Analysis in the Health Sciences, 9th ed.; Wiley: Hoboken, NJ, USA (2009).

34. Zarate H.M.S., Abraham Juárez M.R., Cerón García A., Dzuna López C., Gutoérrez Chávez A.J., et al.: Food Sci. Technol. 38, 210 (2018).

35. Wang X., Sankarapandian K., Cheng Y., Woo S.O., Kwon H.W., et al.: BMC Complement.
Altern. Med. 16, 65 (2016).

36. Bakchiche B., Habati M., Benmebarek A., Gherib A.: WNOFNS 11, 91 (2017).

37. Coneac G., Gafi E., Anu R., Pinzaru I., Bandur G., et al. Chem. Bull. "POLITEHNICA" Univ. (Timisoara) 53, 56 (2009).

38. Przybyłek I. Karpiński T.M.: Molecules 24, 2047 (2019).

C 2020 by Polish Pharmaceutical Society. This is an access article under the CC BY NC license 